\title{
Gold-195m: A Radionuclide of Very Short Life
}

\author{
ITS PRODUCTION AND APPLICATION IN NUCLEAR MEDICINE
}

First pass radionuclide angiocardiography (FPRA) is well established in nuclear medicine as a method for assessing right and left ventricular function at rest and on exercise, as well as for detecting left to right cardiac shunts. Since test results are obtained quickly, the technique is valuable for following changes in cardiac function which occur as a result of medical treatment. Technetium-99m has been widely used in FPRA, but suffers from the serious disadvantage that its physical half-life ( 6 hours) and its retention by the body are such that multiple tests result in an excessive radiation dose to the patient.

Gold-195m, with predominant emission of a $262 \mathrm{keV}$ gamma ray which can be detected efficiently by commercially available scintillation cameras and a short half-life of $30.5 \mathrm{~s}$, does not possess this disadvantage. Its use makes it possible to conduct rapid sequential tests of ventricular function. The fact that a technique has now been developed for producing solutions of gold-195m with 'table-top' equipment at a patient's bedside therefore constitutes an important advance in nuclear medicine.

\section{The Generation of Gold-195m}

The radioisotopic transformations involved in the method developed for production of gold-195m are set out in Figure 1(1). The mercury isotope $\mathrm{Hg}-195 \mathrm{~m}$ is produced,

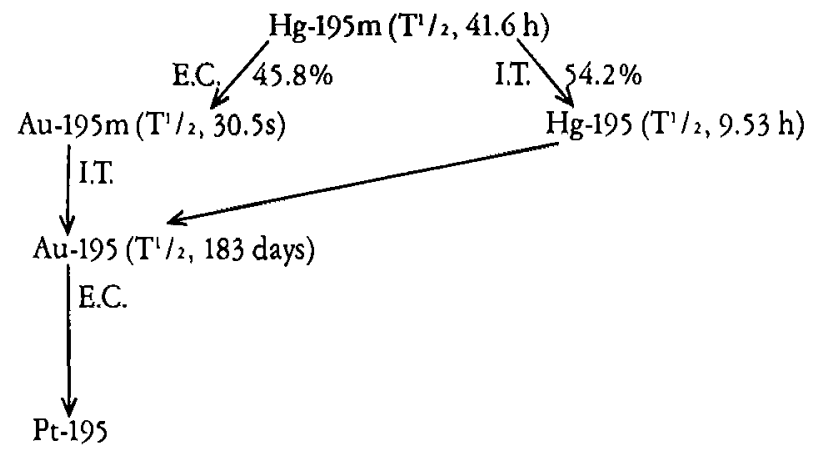

Fig. 1 Reactions involved in production of Au-195m. After (1)

(E.C. = electron capture, I.T. $=$ isomeric transformation)

along with $\mathrm{Hg}-195$, by bombardment of a gold target with protons in a cyclotron. The mercury fraction can be concentrated by dissolution of the target and solvent extraction of the unchanged gold. It is then loaded on to an ion-exchange column, which is 'milked' at need to yield thiosulphate solutions containing Au-195m with the absolute minimum of contamination with $\mathrm{Hg}$-radioisotopes. Byk-Mallinckrodt CIL B.V. of Petten in Holland, have developed equipment (Figure 2) and procedures for this purpose (2), in using which, the risks of mercury breakthrough are minimal and which produces eluates which can be administered directly to patients.

Some appreciation of the nature of the observations which can be made clinically using the method can be gleaned from Figure 3, reproduced from (1). This shows two ventricular wall motions using injected technetium-99m and gold-195m as imaging agents. The upper picture shows an enddiastolic/end-systolic image of a normal subject in which symmetrical ventricularwall contraction is observed using both imaging agents. In the lower illustration diffuse hypokinesis and an apical aneurysm, or localized dilation of the artery, are seen from a patient with prior formation of a region of dead tissue as a result of a process of vascular obstruction (infarction).

\section{References}

1 I. Mena, K.A. Narahara, R. de Jong and J. Maublant, J. Nucl. Med., 1983, 24, $139-144$

2 Byk-Mallinckrodt CIL B.V., U.S. Pat, 4,414,145 (1983)

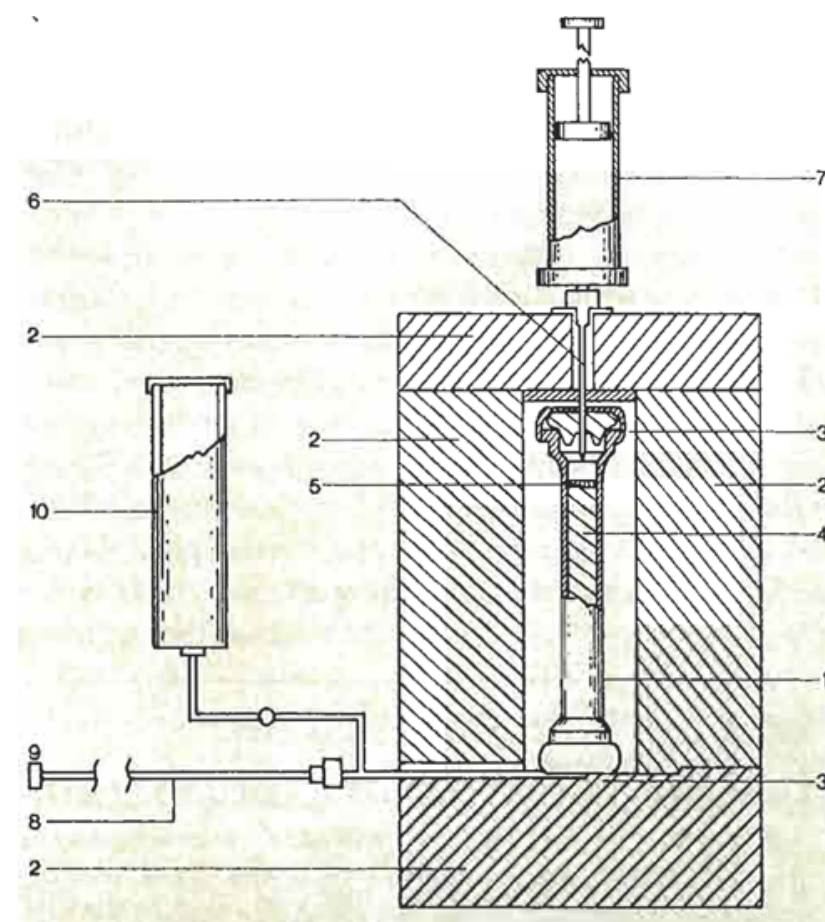

Fig. 2 Radioisotope generator used for the production of gold-195m. (1) generator column, (2) shielding, (3) sealing assembly, (4) adsorption bed (5) filter, (6) needle, (7) eluant reservoir, (8) exit tube, (9) exit fitting, (10) formulation reservoir. After ref. (2).

Fig. 3 Normal (above) and abnormal (below) ventricular wall motion
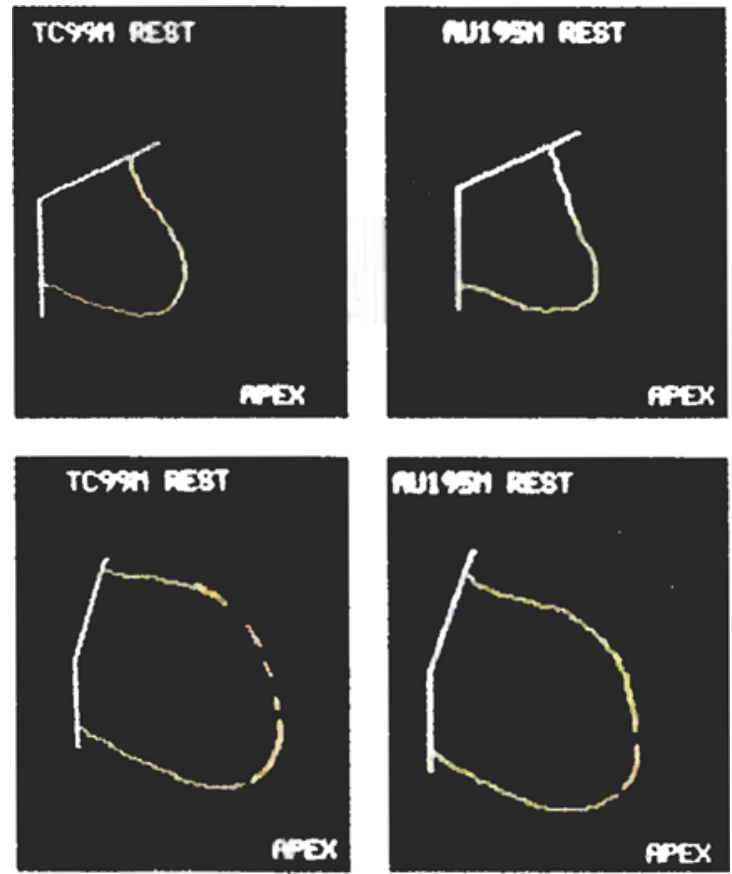